\title{
Andrey Bely's "Lifeline"
}

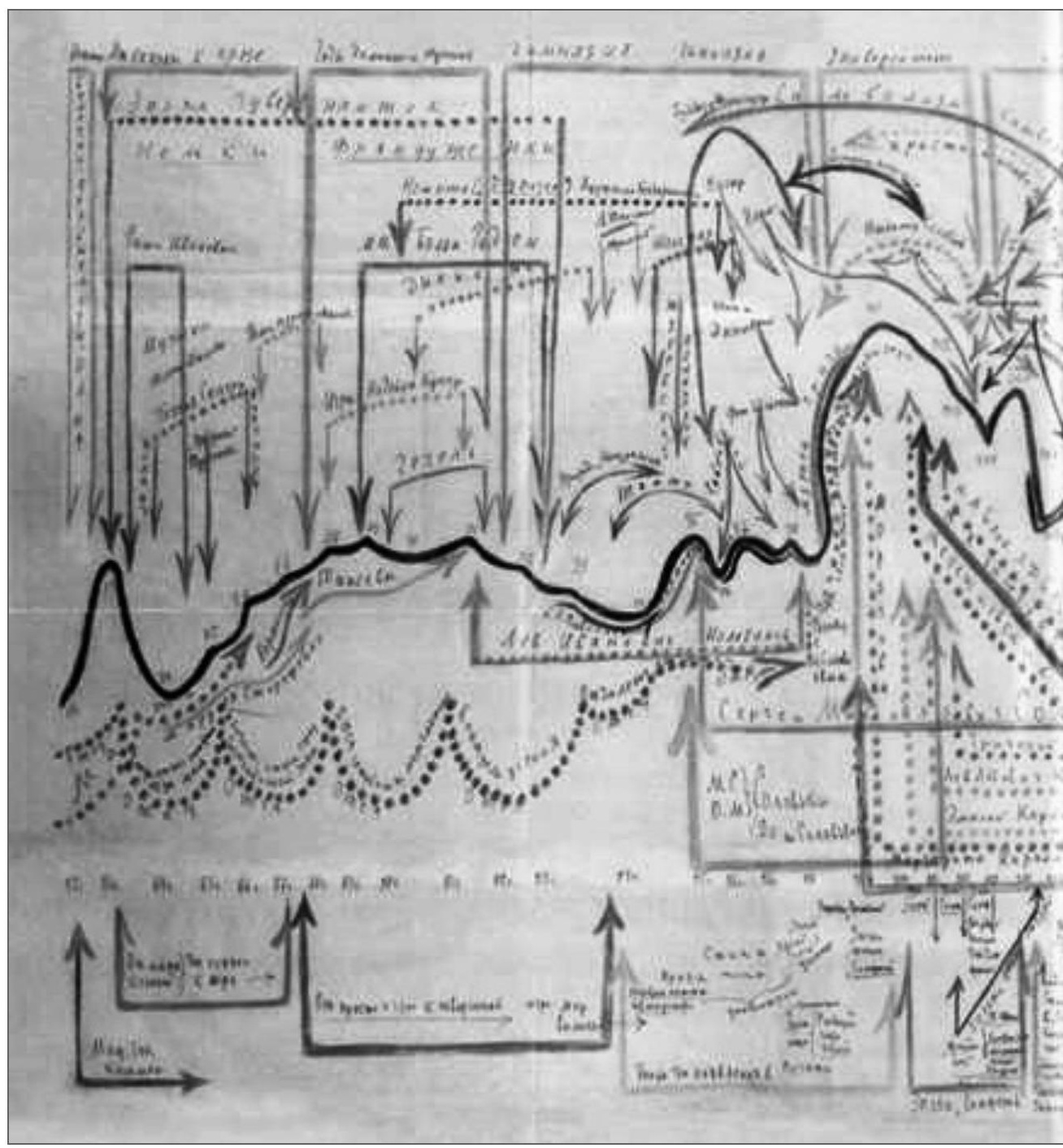

Bely's "Lifeline"-an attempt to summarize his personal and artistic evolution and important influences from his first conscious moments in 1883 at the age of 2-3 up to 1927, when he drew the sketch (illustration to the chapter "Bely's Encounter with Rudolf Steiner," $\rho \rho$. 107-114). 


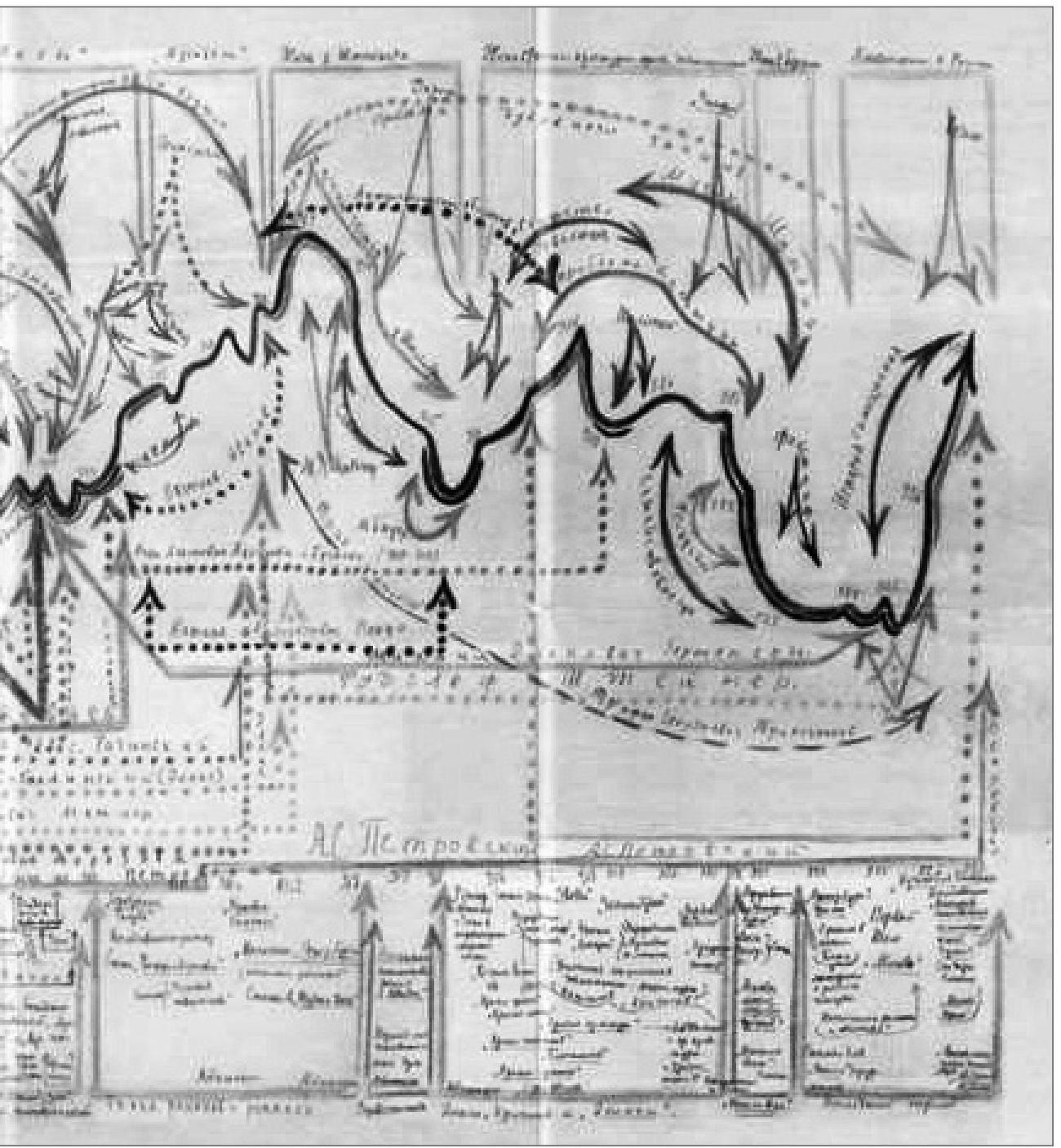




